\title{
Unlinking absorption and haze in thin film silicon solar cells front electrodes
}

\author{
Mathieu Boccard*, Peter Cuony, Corsin Battaglia, Matthieu Despeisse, \\ and Christophe Ballif
}

Ecole Polytechnique Fédérale de Lausanne (EPFL), Institute of Microengineering (IMT),

Photovoltaics and Thin Film Electronics Laboratory, Rue A.-L. Breguet 2, 2000 Neuchâtel, Switzerland

Received 12 July 2010, revised 6 August 2010, accepted 23 August 2010

Published online 26 August 2010

Keywords solar cells, thin film, silicon, light trapping, free carriers, $\mathrm{ZnO}$

* Corresponding author: e-mail mathieu.boccard@epfl.ch, Phone: +41-32-7183320, Fax: +41-32-7183201

We study the respective influence of haze and free carrier absorption (FCA) of transparent front electrodes on the photogenerated current of micromorph thin film silicon solar cells. To decouple the haze and FCA we develop bi-layer front electrodes: a flat indium tin oxide layer assures conduction and allows us to tune FCA while the haze is adjusted by varying the thickness of a highly transparent rough $\mathrm{ZnO}$ layer. We show how a minimum amount of FCA leads only to a few percents absorption for a single light path but to a strong reduction of the cell current in the infrared part of the spectrum. Conversely, a current enhancement is shown with increasing front electrode haze up to a saturation of the current gain. This saturation correlates remarkably well with the haze of the front electrode calculated in silicon. This allows us to clarify the requirements for the front electrodes of micromorph cells.
1 Introduction The micromorph concept (tandem of hydrogenated amorphous/microcrystalline silicon top/bottom cells) emerges as one of the most promising technologies for efficient low cost thin film silicon ( $\mathrm{Si}$ ) modules [1]. Thin film Si solar cells use a transparent conductive oxide (TCO) based front electrode. This thin film should have a high transparency, good conduction and strong light scattering at the textured interface to $\mathrm{Si}$ for optimum light trapping in the cell [2-5]. Electrical properties and transparency are mainly controlled by the density and mobility of free carriers, as they assure the conduction and determine the near-infrared (NIR) absorption (free carrier absorption, FCA); the light scattering potential is commonly quantified by the spectral dependence of the haze in transmission $\left(H_{\mathrm{T}}\right)$ (ratio of diffuse over total transmitted light) and its angular dependence [3, 4].

In the superstrate configuration, low-pressure chemical vapor deposited (LPCVD) zinc oxide ( $\mathrm{ZnO}$ ) based front electrodes are ideally suited for high efficiency thin film $\mathrm{Si}$ solar cells thanks to a high transparency, good electrical properties, a naturally rough surface with excellent light scattering properties and a deposition rate above $3 \mathrm{~nm} / \mathrm{s}[2$, 3]. However, the surface morphology and FCA of a LPCVD $\mathrm{ZnO}$ film depend both on its thickness and doping [2]. The respective influences on the cell current of FCA and light scattering characteristics - that both act in the NIR region of the spectrum - are therefore difficult to separate.

In this Letter, we present bi-layer TCO front electrodes which permit to decouple $H_{\mathrm{T}}$ from FCA. This allows us to evidence the drastic current loss induced by the free carriers in the front electrode and to find an excellent correlation between current enhancement and front electrode $H_{\mathrm{T}}$ for scattering in the cell.

2 Experimental details Micromorph tandem cells with silicon oxide based intermediate reflector (SOIR) [6] are made on glass by plasma enhanced chemical vapor deposition. Bi-layer front electrodes are made of flat sputtered indium tin oxide (ITO) followed by rough nonintentionally doped (NID) LPCVD ZnO. ITO's high free carrier density around $7 \times 10^{20} \mathrm{~cm}^{-3}$ leads to strong absorp- 

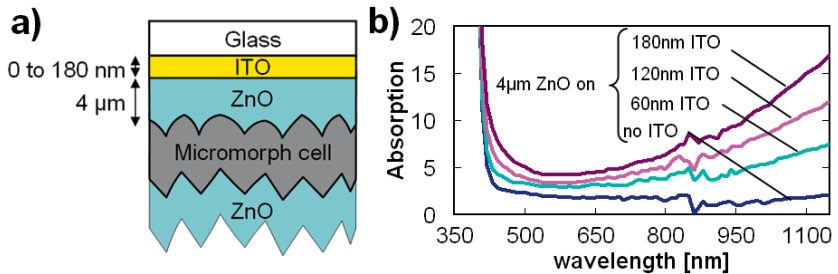

c)

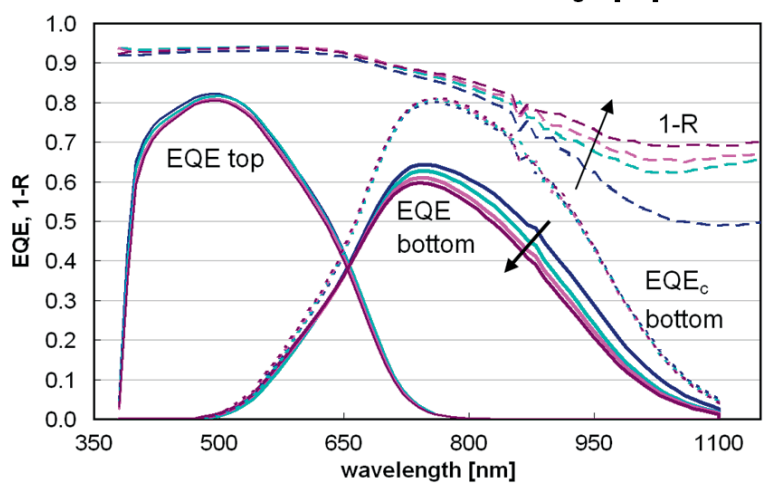

Figure 1 (online colour at: www.pss-rapid.com) a) Shematic cross-section of the studied device. $\mathrm{ZnO}$ is undoped and highly transparent. b) Absorption of front electrodes made of 0 to $180 \mathrm{~nm}$ ITO under $4 \mu \mathrm{m} \mathrm{ZnO.} \mathrm{c)} \mathrm{EQE} \mathrm{and} \mathrm{"} 1$ - reflectance" of micromorph cells grown on the same front electrodes. Arrows show the effect of thickening ITO from 0 to $180 \mathrm{~nm}$. Dotted lines are "corrected" EQEs of bottom cells simulating no parasitic absorption.

tion, while a 30 times smaller carrier density makes rough NID ZnO highly transparent [7]. Back contact is made of $6 \mu \mathrm{m}$ NID $\mathrm{ZnO}$. The cells short circuit currents are extracted from external quantum efficiencies (EQE) and transmission-reflection measurements are made as described in Ref. [3].

3 FCA influence on the cell current To study the FCA influence on the cell current we deposit various thicknesses of ITO on glass: no ITO, $60 \mathrm{~nm}, 120 \mathrm{~nm}$ and $180 \mathrm{~nm}$. We subsequently deposit a $4 \mu \mathrm{m}$ thick NID LPCVD $\mathrm{ZnO}$ on top of each ITO layer (Fig. 1a) to ensure identical light scattering properties for all four bi-layer front electrodes. A systematic increase in the NIR absorptance is observed for increasing ITO thickness (Fig. 1b) while the $\mathrm{ZnO}$ layer shows a remarkably low absorptance below $2 \%$ up to $1100 \mathrm{~nm}$ for a sheet resistance as low as $23 \Omega / \square$.

Figure 1c shows that an increase of the front electrode absorptance lowers the $\mathrm{EQE}$ of the microcrystalline bottom cell and the reflectance $(R)$ of the stack $(1-R$ increases $)$ in the NIR. Table 1 summarizes for all front electrodes the cell currents as well as the current losses compared to the cell with no ITO. $0.8 \mathrm{~mA} \mathrm{~cm}^{-2}$ (corresponding to $6 \%$ relative) is lost when introducing $60 \mathrm{~nm}$ ITO to the simple $\mathrm{ZnO}$ front electrode. Introducing twice (three times) as much ITO lowers even more the current by $1.1 \mathrm{~mA} \mathrm{~cm}^{-2}$ $\left(1.4 \mathrm{~mA} \mathrm{~cm}^{-2}\right)$.

Between $700 \mathrm{~nm}$ and $850 \mathrm{~nm}$, linear EQE bottom loss and $1-R$ increase are observed with increasing ITO thick-
Table 1 Top and bottom cell currents for micromorph cells grown on various bilayer front electrodes of which absorptance at $900 \mathrm{~nm}$ is indicated. The bottom cell current shift compared to the first cell of each series is also indicated.

\begin{tabular}{rlllll}
\hline $\begin{array}{l}\text { ITO } \\
{[\mathrm{nm}]}\end{array}$ & $\begin{array}{l}\mathrm{ZnO} \\
{[\mu \mathrm{m}]}\end{array}$ & $\begin{array}{l}A(900 \mathrm{~nm}) \\
{[\%]}\end{array}$ & $\begin{array}{l}J_{\text {sc,top }} \\
{\left[\mathrm{mA} / \mathrm{cm}^{2}\right]}\end{array}$ & $\begin{array}{l}J_{\text {sc,bot }} \\
{\left[\mathrm{mA} / \mathrm{cm}^{2}\right]}\end{array}$ & $\begin{array}{l}J_{\text {sc,bot }} \text { shift } \\
{\left[\mathrm{mA} / \mathrm{cm}^{2}\right]}\end{array}$ \\
\hline 0 & 4 & 0.9 & 12.4 & 12.6 & 0.0 \\
60 & 4 & 3.7 & 12.3 & 11.8 & -0.8 \\
120 & 4 & 6.1 & 12.1 & 11.5 & -1.1 \\
180 & 4 & 8.2 & 11.9 & 11.2 & -1.4 \\
\hline 60 & 0.1 & 2.5 & 8.4 & 8.4 & 0.0 \\
60 & 1 & 3.1 & 12.4 & 11.0 & +2.6 \\
60 & 2 & 4.1 & 12.7 & 11.8 & +3.4 \\
60 & 4 & 3.7 & 12.2 & 12.0 & +3.6 \\
60 & 7 & 4.3 & 12.3 & 12.7 & +4.3 \\
\hline
\end{tabular}

ness. After $850 \mathrm{~nm}$, a deviation from linearity is due to the lower refractive index of ITO $(\sim 1.6$ at $1100 \mathrm{~nm})$ compared to $\mathrm{ZnO}(\sim 2.0)$ because of its high doping, modifying the total internal reflection in the cell. In the cell, the significant current loss due to ITO in the NIR comes from efficient light trapping inducing multiple light paths not only in the photoactive layers but also in the TCO. Its absorptance is then stronger than the one measured outside the cell (Fig. 1b). High current gains are thus expected in cells by reducing the front electrode FCA, even for little absorbing TCOs.

A way to compare the light scattering properties of different front electrodes is to calculate corrected $\mathrm{EQE}\left(\mathrm{EQE}_{\mathrm{c}}\right)$ and $R\left(R_{\mathrm{c}}\right)$ assuming no "parasitic" absorption $\left(A_{\mathrm{p}}\right)$ in our device (mainly from TCO and doped layers). For good carrier collection, we have $\mathrm{EQE}+A_{\mathrm{p}}+R=1$ so $\mathrm{EQE}+R=1-A_{\mathrm{p}}$. Without parasitic absorption, $\mathrm{EQE}_{\mathrm{c}}+R_{\mathrm{c}}=1$. This normalization is obtained by defining $\mathrm{EQE}_{\mathrm{c}}=\mathrm{EQE} /\left(1-A_{\mathrm{p}}\right)$ and $R_{\mathrm{c}}=R /\left(1-A_{\mathrm{p}}\right)$ which means splitting equitably $A_{\mathrm{p}}$ between current conversion and reflectance. Finally, $\mathrm{EQE}_{\mathrm{c}}=\mathrm{EQE} /(\mathrm{EQE}+R)$. The $\mathrm{EQE}_{\mathrm{c}}$ of aforementioned bottom cells are dotted curves in Fig. 1c. Their excellent superimposition confirms that light scattering is identical for all the front electrodes and that the EQE reduction can be attributed exclusively to FCA.

4 Haze influence on the cell current Micromorph cells are deposited on ITO-ZnO bi-layer front electrodes (Fig. 2a). A $60 \mathrm{~nm}$ thick ITO layer ensures conduction and an almost identical FCA up to $1100 \mathrm{~nm}$ for all cases (e.g. at $900 \mathrm{~nm}$, Table 1). $\mathrm{ZnO}$ thicknesses varied from $0.1 \mu \mathrm{m}$ to $7 \mu \mathrm{m}$ to improve light scattering (Fig. 2b) thanks to increased size of pyramidal features $(\sim 0.4 \mu \mathrm{m}$ for $2 \mu \mathrm{m}$ films) [2]. Angular dependence of light scattering (not shown) is identical for all cases.

Improving the front electrode haze enhances the bottom cell current (Table 1). Part of this gain comes from the $500-800 \mathrm{~nm}$ range of the EQE and is accompanied by a top cell current loss coming from the same range (especially for $\mathrm{ZnO}$ layers thicker than $2 \mu \mathrm{m}$ as shown in Ta- 


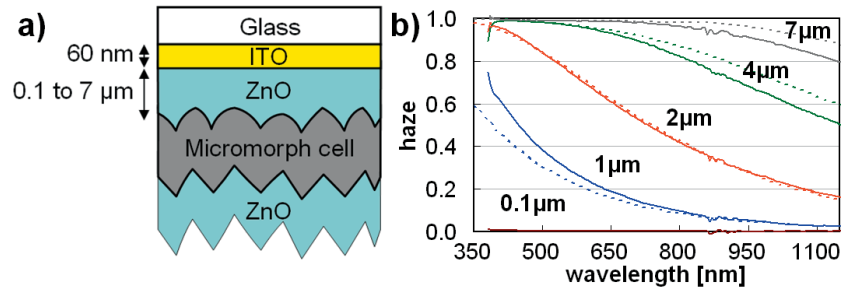

c)

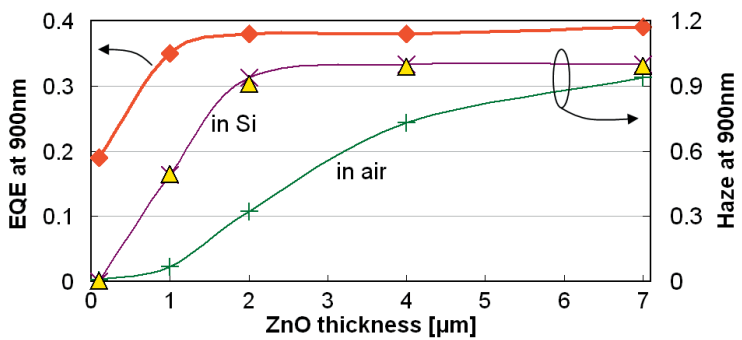

Figure 2 (online colour at: www.pss-rapid.com) a) Schematic cross-section of the studied device. b) $H_{\mathrm{T}}$ measured (and calculated, dotted lines) in air for $0.1 \mu \mathrm{m}$ to $7 \mu \mathrm{m}$ thick $\mathrm{ZnO}$ layers on $60 \mathrm{~nm}$ thick ITO layer. c) $H_{\mathrm{T}}$ at $900 \mathrm{~nm}$ measured in air or calculated in Si of the same TCO stacks (right axis) and EQE value at $900 \mathrm{~nm}$ for cells grown on these substrates (left axis). Triangles are $H_{\mathrm{T}}$ values measured in air at $450 \mathrm{~nm}$.

ble 1). This can be due to the very different roughnesses of the front electrodes [8]. EQE values at $900 \mathrm{~nm}$ (Fig. 2c) are then used to quantify the impact of our front electrodes scattering characteristics.

The cell response at $900 \mathrm{~nm}$ increases for increasing $\mathrm{ZnO}$ thickness in the front electrode up to saturation for $2 \mu \mathrm{m}$ thick films (Fig. 2c). No EQE enhancement is seen from $2 \mu \mathrm{m}$ to $7 \mu \mathrm{m}$ thick films despite the continuous $H_{\mathrm{T}}$ increase measured in air (Fig. 2c). Indeed, light scattering due to a rough interface in $\mathrm{Si}$ (as it is the case in a cell) is different from that in air because of the different refractive indices of air and Si. Yet, the $H_{\mathrm{T}}$ of a front electrode in $\mathrm{Si}$ cannot be directly measured but it can be calculated for any ambient medium from AFM data with a recently developed Fourier method [9]. The results of such $H_{\mathrm{T}}$ calculations for our front electrodes in air are shown in Fig. $2 b$. The excellent agreement with measurements validates the method which we now use to determine the $H_{\mathrm{T}}$ of our front electrodes for scattering in Si. These calculated $H_{\mathrm{T}}$ values in $\mathrm{Si}$ at $900 \mathrm{~nm}$ are plotted in Fig. 2c and correlate well with the EQE enhancement at the same wavelength.

In the model presented in [9], as well as in scalar scattering theory (see e.g. in [3]), the $H_{\mathrm{T}}$ created at an interface depends mostly on a phase shift $\delta$ of the incoming light induced by its roughness. This phase shift is proportional to $2 \pi\left|n_{1}-n_{2}\right| \zeta / \lambda$, $\zeta$ being a length characterizing the roughness of the surface, $n_{1}$ and $n_{2}$ the refractive indices of the surrounding media and $\lambda$ the wavelength of the incident light. For TCO $\left(n_{1}=2\right)$ in air $\left(n_{2}=1\right)$, we have $\delta \propto 2 \pi \cdot \zeta / \lambda$ and for TCO in $\mathrm{Si}\left(n_{2}=4\right)$, as in the cell, $\delta \propto 2 \pi \cdot 2 \zeta / \lambda$. So the phase shift, thus the $H_{\mathrm{T}}$, due to the rough surface of a TCO layer in Si for a wavelength $\lambda$ is equal to its $H_{\mathrm{T}}$ in air but at the wavelength $\lambda / 2$. The $H_{\mathrm{T}}$ measured in air at $450 \mathrm{~nm}$ for the same series of front electrodes is plotted as triangles in Fig. 2c. It matches very well the calculated value in Si at $900 \mathrm{~nm}$.

Thus, as a rule of thumb, $H_{\mathrm{T}}$ values of TCO based front electrodes measured in air at a given wavelength can be correlated to the EQE enhancement of the thin film Si solar cell but at twice the wavelength. Consequently, measuring $H_{\mathrm{T}}$ values of TCO based front electrodes in air at wavelengths over $550 \mathrm{~nm}$ is irrelevant to characterize their light scattering potential for $\mathrm{Si}$ solar cell applications.

5 Conclusion We could separate the relative influence of front electrode haze and FCA by using LPCVD $\mathrm{ZnO}$ and ITO. An EQE decrease and a reduction of total reflectance from the cell is observed when increasing FCA for a unique morphology. The current loss is shown to be quite dramatic even for a few percents of TCO absorptance, therefore demonstrating the need to develop TCOs with very low absorptances $(<2 \%)$. On the other hand, enhancing the haze for a given FCA improves the bottom cell current. The EQE gain at large wavelengths is well correlated to the haze value of the front electrode calculated in Si but not to its value in air. A convenient scaling law is proposed to approximate haze in $\mathrm{Si}$ at a wavelength $\lambda$ by its measurement in air at $\lambda / 2$. Bi-layer front electrodes combining a flat, conducting and highly transparent TCO (e.g. indium oxide [10]) with $2 \mu \mathrm{m}$ thick NID LPCVD ZnO featuring small pyramids with sufficient haze would thus be excellent to reach high top and bottom cell currents in micromorph solar cells.

Acknowledgement The authors would like to thank OFEN for financial support under project 101191.

\section{References}

[1] A. G. Aberle, Thin Solid Films 517, 4706 (2009).

[2] S. Faÿ et al., Sol. Energy Mater. Sol. Cells 90, 2960 (2006).

[3] D. Domine, P. Buehlmann, J. Bailat, A. Billet, A. Feltrin, and C. Ballif, Phys. Status Solidi RRL 2, 163 (2008).

[4] M. Berginski et al., J. Appl. Phys. 101, 74903 (2007).

[5] J. A. Selvan, A. E. Delahoy, S. Guo, and Y. M. Li, Sol. Energy Mater. Sol. Cells 90, 3371 (2006).

[6] P. Buehlmann, J. Bailat, D. Domine, A. Billet, F. Meillaud, A. Feltrin, and C. Ballif, Appl. Phys. Lett. 91, 143505 (2007).

[7] J. Steinhauser, S. Fay, N. Oliveira, E. Vallat-Sauvain, and C. Ballif, Appl. Phys. Lett. 90, 142107 (2007).

[8] D. Domine et al., Conference Record of the 2006 IEEE 4th World Conference 3, p. 1465 (2006).

[9] D. Domine, F. J. Haug, C. Battaglia, and C. Ballif, J. Appl. Phys. 107, 044504 (2010).

[10] T. Koida et al., Thin Solid Films 518, 2930 (2010). 